\title{
Pengaruh Obat Anti Epilepsi Terhadap Gangguan Daya Ingat pada Epilepsi Anak
}

\author{
Mustarsid, Fadhilah Tia Nur, Shinta Riana Setiawati, Harsono Salimo \\ Bagian Ilmu Kesehatan Anak FK Universitas Sebelas Maret-RSUD Dr. Moewardi Surakarta
}

Latar belakang. Epilepsi merupakan penyakit kronik yang dapat menurunkan kualitas hidup, di antaranya gangguan daya ingat.

Tujuan. Mengetahui prevalensi gangguan daya ingat, serta pengaruh lama pengobatan, dan jumlah obat anti epilepsi.

Metode. Penelitian potong lintang untuk mengetahui prevalensi gangguan daya ingat, serta pengaruh lama pengobatan, dan jumlah obat anti epilepsi terhadap gangguan daya ingat pada pasien epilepsi anak. Penelitina dilakukan di Poliklinik Neurologi Anak RSUD Dr Moewardi Surakarta dalam kurun waktu September 2010 - November 2010, pada 50 subyek.

Hasil. Gangguan daya ingat dialami 46\% subyek di antara 50 subyek yang diteliti. Analisis bivariat mendapatkan pengaruh lama pengobatan lebih dari 2 tahun dengan OR 13,14 (CI 95\% 3,29-2,47), jumlah obat anti epilepsi lebih dari satu obat dengan OR 0,6 (CI 95\% 0,18-2,02). Analisis regresi logistik ganda mendapatkan faktor yang mempengaruhi daya ingat adalah lama pengobatan lebih dari 2 tahun dengan OR 17,3 (CI 95\% 1,13- 279,17).

Kesimpulan. Gangguan daya ingat dialami 46\% pasien epilepsi anak. Lama pengobatan lebih dari dua tahun berpengaruh terhadap terjadinya gangguan daya ingat pada pasien epilepsi anak. Sari Pediatri 2011;12(5):302-306.

Kata kunci: epilepsi, daya ingat, lama pengobatan, obat anti epilepsi

$\mathrm{E}$ pilepsi merupakan penyakit kronis di bidang neurologi dan penyakit kedua terbanyak setelah stroke. ${ }^{1,2}$ Epilepsi disebabkan oleh berbagai etiologi dengan gejala tunggal yang khas yaitu serangan yang terjadi tiba-tiba dan berulang

\footnotetext{
Alamat korespondensi:

Dr. Mustarsid, Sp.A. Divisi Neurologi. Bagian Ilmu Kesehatan Anak FK UNS-RSUD Dr. Moewardi Surakarta. Jl. Kol Sutarto 135 Surakarta. Telp.: 0271666866.
}

yang disebabkan oleh lepas muatan listrik kortikal secara berlebihan. ${ }^{3}$ Anak yang menderita epilepsi memerlukan evaluasi dan terapi yang sesuai karena serangan yang berulang akan mempengaruhi kualitas hidup pasien baik fisis, mental, maupun sosial. Epilepsi yang tidak terkontrol juga meningkatkan risiko mortalitas 2-3 kali populasi normal dan menurunkan kualitas pasiennya. ${ }^{4-9}$

Prevalensi epilepsi bervariasi antara 0,5\%-1\% populasi umum. ${ }^{10}$ Insiden epilepsi pada anak di negara 
berkembang lebih tinggi daripada negara maju. Insiden epilepsi di negara berkembang masih tinggi diduga karena faktor risiko gangguan atau infeksi saraf pusat yang dapat menjadi fokus epileptik masih banyak terjadi. ${ }^{4,7}$ Kualitas hidup pasien epilepsi dapat menurun di antaranya karena gangguan daya ingat yang dapat disebabkan oleh epilepsi, pengaruh obat anti epilepsi, serta faktor psikososial., ${ }^{4,10-16}$ Dilaporkan gangguan daya ingat terjadi pada 20\%-50\% pasien epilepsi anak. ${ }^{10,14,17}$

Penelitian dilakukan untuk mengetahui prevalensi gangguan daya ingat dan pengaruh obat anti epilepsi yang menyebabkan terjadinya gangguan daya ingat pada pasien epilepsi anak yang dirawat di RSUD Dr. Moewardi Surakarta.

\section{Metode}

Penelitian potong lintang dilakukan untuk melihat pengaruh lama pengobatan dan jumlah obat anti epilepsi terhadap gangguan daya ingat pada pasien epilepsi anak. Subyek penelitian adalah pasien epilepsi anak yang berobat di Poliklinik Neurologi Anak RSUD Dr. Moewardi Surakarta, pada bulan September 2010 November 2010 subyek dipilih secara konsekutif yang memenuhi kriteria inklusi, meliputi umur 6-12 tahun, mengerti huruf dan angka serta dapat menulis, dan mendapat izin dari orangtua atau wali untuk ikut serta dalam penelitian. Subyek tidak diikutsertakan apabila menderita retardasi mental dan depresi. Penghitungan besar sampel menggunakan rumus rule of the thumb, yaitu 10-50 kali jumlah faktor risiko yang diteliti, maka diperlukan 20-100 subyek. Diagnosis epilepsi ditegakkan oleh dokter spesialis anak. Penelitian telah disetujui oleh Komite Etik Penelitian Rumah Sakit Dr. Moewardi Surakarta.

Tes daya ingat yang digunakan adalah subtes dari Wechsler Intellegence Scale for Children-III, yaitu tes perhatian dan konsentrasi. Tes daya ingat dilakukan oleh seorang psikolog. Tes perhatian meliputi tes visual dan verbal. Tes visual menggunakan gambar kucing dan wajah (visual search). Pada tes visual gambar kucing, subyek diminta mencari gambar kucing dari sekumpulan gambar. Tes ini hanya merupakan latihan untuk mencari gambar, dengan lama tes 120 detik. Kemudian dilanjutkan tes visual kedua dengan meminta subyek mencari gambar mimik wajah yang sesuai dari sekumpulan gambar mimik wajah yang berbeda-beda, waktu 120 detik. Skor tes ini adalah jumlah gambar yang benar dikurangi jumlah yang salah. Tes verbal dilakukan dengan digitspan forward (hitung maju). Subyek diminta menirukan angka yang disebutkan pemeriksa, dimulai dengan 3 digit angka sampai maksimal 9 digit, masingmasing digit dilakukan tes dua kali. Tes dihentikan apabila subyek tidak dapat menirukan kembali dua kali digit angka dengan urutan yang benar. Jumlah digit yang dapat disebutkan dengan urutan yang benar merupakan hasil tes verbal. Tes konsentrasi dengan menggunakan digit span backward. Subyek diminta menirukan angka yang disebutkan pemeriksa, tetapi dengan urutan yang terbalik, dimulai dengan 2 digit sampai maksimal 8 digit. Masing-masing digit dilakukan tes dua kali. Tes dihentikan apabila subyek tidak dapat menyebutkan dengan benar urutan angka yang dibalik. Skor tes adalah jumlah digit yang dapat disebutkan dengan urutan dibalik.

Data yang didapat dianalisis dengan menggunakan program SPSS versi 15.0. Variabel bebas berskala nominal dideskripsikan dalam proporsi. Variabel tergantung yaitu daya ingat, yang diperiksa dengan tes memori verbal, visual, dan tes konsentrasi merupakan skala kontinu. Hasil pemeriksaan didiskripsikan dalam median dan dibuat sebarannya. Disebutkan terjadi gangguan daya ingat apabila skor salah satu tes berada kurang dari median (apabila distribusi data tidak normal) atau kurang dari mean (apabila distribusi data normal).

Untuk melihat pengaruh masing-masing variabel bebas terhadap variabel tergantung dilakukan uji bivariat, dilanjutkan dengan uji analisis regresi logistik ganda untuk melihat pengaruh kedua variabel bebas terhadap varibel tergantung. Pada analisis ditentukan odds ratio (OR) disertai dengan nilai confidence interval 95\% (CI 95\%).

\section{Hasil}

Pada Tabel 1 tertera kelompok umur 6-8 tahun merupakan kelompok umur terbanyak $(\mathrm{n}=28,56 \%)$, dan jumlah laki-laki sama dengan perempuan. Jumlah subyek yang memiliki faktor risiko mengalami gangguan daya ingat yaitu lama pengobatan $>2$ tahun, 20 orang $(40 \%)$ dan jumlah subyek yang mendapat obat anti epilepsi $>1,15$ orang $(30 \%)$.

Pada tes perhatian visual dan verbal serta tes konsentrasi didapatkan hasil tertera pada Tabel 2.

Pengaruh masing-masing faktor risiko terhadap terjadinya gangguan visual, verbal, konsentrasi, dan daya ingat, tertera pada Tabel 3. 
Tabel 1. Karakteristik dasar subyek penelitian $(n=50)$

\begin{tabular}{lcc}
\hline Karakteristik subyek & \multicolumn{2}{c}{ Jumlah } \\
\cline { 2 - 3 } & $\mathrm{n}$ & $\%$ \\
\hline Umur pasien (tahun) & 28 & 56 \\
$\quad$ 6-8 & 22 & 44 \\
$\quad>8-12$ & & \\
Jenis kelamin & 25 & 50 \\
$\quad$ Laki-laki & 25 & 50 \\
$\quad$ perempuan & & \\
Lama pengobatan (tahun) & 20 & 40 \\
$\quad<2$ & 30 & 60 \\
$\quad 22$ & & \\
Obat anti epilepsi (macam) & 34 & 68 \\
$\quad 1$ & 16 & 32 \\
$\quad>1$ & & \\
\hline
\end{tabular}

Tabel 2. Tes perhatian visual, verbal, konsentrasi, dan daya ingat $(\mathrm{n}=50)$

\begin{tabular}{lcc}
\hline Tes daya ingat & \multicolumn{2}{c}{ Jumlah } \\
\cline { 2 - 3 } & $\mathrm{N}$ & $\%$ \\
\hline Perhatian visual & & \\
Terganggu $(<28)$ & 22 & 44 \\
Tidak terganggu $(\geq 28)$ & 28 & 56 \\
Perhatian verbal & & \\
Terganggu $(<4)$ & 9 & 18 \\
Tidak terganggu $(\geq 4)$ & 41 & 82 \\
Tes konsentrasi & & \\
Terganggu $(<3)$ & 8 & 16 \\
Tidak terganggu $(\geq 3)$ & 42 & 84 \\
Daya ingat & & \\
Terganggu & 23 & 54 \\
Tidak terganggu & 27 & \\
\hline
\end{tabular}

Hasil analisis bivariat antara pemeriksaan visual dengan masing-masing faktor risiko menunjukkan pengaruh lama pengobatan (OR 9,86; CI 95\% 2,64 $-36,87)$ terhadap terjadinya gangguan perhatian visual. Hasil analisis bivariat pemeriksaan perhatian verbal dengan masing-masing faktor risiko menunjukkan pengaruh lama pengobatan (OR 3,86; CI 95\% 0,84 $-17,80)$ terhadap gangguan verbal. Hasil analisis bivariat pemeriksaan konsentrasi dengan masing-masing faktor risiko menunjukkan pengaruh lama pengobatan (OR 15,64; CI 95\% 1,74-140,23) terhadap terjadinya gangguan konsentrasi. Analisis bivariat antara daya ingat dan faktor risiko juga menunjukkan pengaruh lama pengobatan (OR 13,14; CI 95\% 3,29-52,47) terhadap terjadinya gangguan daya ingat.

Hasil analisis multivariat regresi logistik ganda pengaruh obat anti epilepsi terhadap terjadinya gangguan daya ingat pada pasien epilepsi anak (Tabel 4), menunjukkan pengaruh lama pengobatan $>2$ tahun (OR 17,73; CI 95\% 1,13-279,17) terhadap terjadinya gangguan daya ingat. Umur subyek penelitian diikutsertakan dalam analisis karena jumlah subyek dengan umur 6-8 tahun lebih banyak dibandingkan umur >8-12 tahun (28 subyek dibandingkan dengan 22 subyek), sehingga dapat dilihat apakah faktor umur berpengaruh terhadap terjadinya gangguan daya ingat. Analisis menunjukkan pengaruh umur > $8-12$ tahun bersifat protektif terhadap terjadinya gangguan daya ingat (OR 0,01; CI 95\% 0,00-0,06). Hasil analisis juga menunjukkan pengaruh jumlah obat anti epilepsi $\geq 1$ (OR 0,60; CI 95\% 0,05-7,95) terhadap terjadinya gangguan daya ingat.

Tabel 3. Analisis bivariat faktor risiko dengan perhatian visual, verbal, konsentrasi, dan daya ingat $(\mathrm{n}=50)$

\begin{tabular}{lccc}
\hline Faktor risiko & OR & $95 \%$ CI & $p$ \\
\hline Gangguan perhatian visual & & & \\
$\quad$ Lama pengobatan & 9,86 & $2,64-36,87$ & 0,001 \\
Jumlah obat anti epilepsi & 0,68 & $0,20-2,28$ & 0,526 \\
Gangguan perhatian verbal & & & \\
$\quad$ Lama pengobatan & 3,86 & $0,84-17,8$ & 0,084 \\
$\quad$ Jumlah obat anti epilepsi & 0,55 & $0,10-3,01$ & 0,492 \\
Gangguan konsentrasi & & & \\
Lama pengobatan & 15,64 & $1,74-140,23$ & 0,014 \\
$\quad$ Jumlah obat anti epilepsi & 0,26 & $0,03-2,30$ & 0,224 \\
Gangguan daya ingat & & & \\
Lama pengobatan & 13,14 & $3,29-52,47$ & $<0,001$ \\
Jumlah obat anti epilepsi & 0,60 & $0,18-2,02$ & 0,410 \\
\hline
\end{tabular}


Tabel 4. Analisis regresi logistik ganda pengaruh obat anti epilepsi terhadap terjadinya gangguan daya ingat pasien epilepsi anak

\begin{tabular}{lccc}
\hline Variabel & OR & $95 \%$ CI & Nilai $p$ \\
\hline Lama pengobatan & 17,73 & $1,13-279,17$ & 0,041 \\
Umur $>8-12$ tahun & 0,01 & $0,00-0,16$ & 0,002 \\
Jumlah macam obat anti epilepsi & 0.60 & $0,05-7,95$ & 0,698 \\
\hline
\end{tabular}

- n observasi: $50 \quad$ Adj R2: 0,65

- Log likelihood: $-12,10 \quad$ - p: 0,000

\section{Pembahasan}

Data penelitian merupakan data sekunder dari rekam medis untuk mengetahui faktor risiko obat anti epilepsi yang mempengaruhi daya ingat, yaitu lama pengobatan, dan jumlah obat anti epilepsi. Daya ingat yang diperiksa adalah daya ingat (memori) jangka pendek karena memori jangka pendek dibutuhkan untuk mengingat atau menjadikan informasi yang didapat menjadi memori jangka panjang melalui proses konsolidasi. ${ }^{17}$ Suatu informasi yang diterima untuk dapat menjadi memori jangka pendek, diperlukan proses pengenalan dan registrasi. Agar kedua proses ini berjalan optimal, diperlukan perhatian dan konsentrasi yang cukup. Pada epilepsi, gangguan daya ingat yang paling sering dijumpai adalah amnesia retrograd, yaitu kesulitan mengingat hal-hal baru yang dipelajari, karena proses pengenalan dan konsolidasi lebih rentan terganggu oleh aktivitas listrik abnormal. ${ }^{17,20}$

Working memory merupakan gabungan antara memori jangka pendek dan memori jangka panjang yang dikeluarkan kembali, kemudian dipertahankan dalam pikiran seseorang dalam jangka waktu tertentu untuk mengerjakan tugas tertentu yang membutuhkan keputusan cepat. Kapasitas working memory menentukan tingkat kecerdasan seseorang. Pada pasien epilepsi, bangkitan juga akan mengganggu proses penyimpanan dan pemunculan kembali informasi yang telah tersimpan. ${ }^{10}$

Penelitian kami menunjukkan gangguan daya ingat pada $46 \%$ subyek, sesuai dengan Connor ${ }^{14}$ dan Zeman ${ }^{17}$ yang melaporkan gangguan daya ingat terjadi pada 20\%-50\% pasien epilepsi anak.

Jumlah subyek yang diteliti, yang berumur lebih muda lebih banyak, maka terhadap faktor umur dilakukan analisis multivariat untuk mengetahui apakah umur muda berpengaruh terhadap terjadinya gangguan daya ingat. Hasil analisis menunjukkan umur
>8-12 tahun merupakan faktor protektif terhadap terjadinya gangguan daya ingat dibandingkan anak umur 6-8 tahun.

Hasil analisis bivariat menunjukkan lama pengobatan lebih dari 2 tahun meningkatkan risiko sebesar sepuluh kali lebih besar daripada anak dengan lama pengobatan $<2$ tahun (terhadap terjadinya gangguan perhatian visual, sedangkan terhadap terjadinya gangguan perhatian verbal tidak didapatkan pengaruh kedua faktor risiko tersebut. Lama pengobatan $>2$ tahun juga meningkatkan risiko sebesar hampir enambelas kali dibandingkan dengan lama pengobatan $<2$ tahun terhadap terjadinya gangguan konsentrasi, sedangkan terhadap terjadinya gangguan daya ingat, lama pengobatan meningkatkan risiko sebesar tigabelas kali. Hasil analisis regresi logistik ganda faktor obat anti epilepsi yang berpengaruh terjadinya gangguan daya ingat, menunjukkan lama pengobatan $>2$ tahun meningkatkan risiko 17 kali lebih tinggi dibandingkan lama pengobatan $<2$ tahun. Umur pasien $>8-12$ tahun merupakan faktor protektif terjadinya gangguan daya ingat.

Penjelasan hasil tersebut, semakin lama pengobatan epilepsi semakin besar kemungkinan terjadi gangguan memori. Obat anti epilepsi mempunyai efek negatif maupun positif terhadap kemampuan kognitif pasien epilepsi. Obat anti epilepsi dapat meningkatkan kemampuan kognitif dan tingkah laku pasien epilepsi dengan cara mengurangi bangkitan kejang, efek modulasi terhadap neurotransmiter, dan efek psikotropika. Obat anti epilepsi mengurangi iritabilitas neuron dan meningkatkan inhibisi pasca-sinaps atau mempengaruhi sinkronisasi jaringan neuron untuk menurunkan eksitasi neuron yang berlebihan sehingga dapat menurunkan bangkitan kejang dan dapat menurunkan aktivitas epilepsi di sekeliling jaringan otak yang normal. Aktivitas obat anti epilepsi tersebut apabila dirangsang secara terus menerus dapat mengakibatkan penurunan aktivitas 
motorik dan psikomotor, penurunan perhatian, dan gangguan memori. Penurunan daya ingat dapat bersifat reversibel dan kumulatif, sehingga semakin lama pasien mendapatkan terapi anti epilepsi maka gangguan memori akan semakin besar. ${ }^{21}$ Obat anti epilepsi yang paling mempengaruhi fungsi kognitif dan memori adalah fenobarbital dan fenitoin. ${ }^{15,18,22}$ Fenobarbital merupakan obat anti epilepsi generasi lama yang efektif untuk epilepsi fokal. Dampak obat antiepileptik terjadi dengan cara meningkatkan inhibisi. Fenobarbital berikatan dengan reseptor GABA memperpanjang waktu membukanya $\mathrm{Cl}$ channel sehingga terjadi hiperpolarisasi. ${ }^{7}$ Pemakaian fenobarbital menimbulkan efek samping sedasi dan hipnosis yang mengakibatkan gangguan perhatian dan konsentrasi. ${ }^{22}$ Fenitoin juga termasuk obat anti epilepsi generasi lama yang efektif untuk epilepsi fokal. Efek antiepileptik terjadi dengan cara mereduksi eksitasi, yaitu menghalangi $\mathrm{Na}^{+}$channel sehingga mencegah aktivitas elektrik paroksismal, menghalangi potensiasi pasca kejang, dan mencegah menjalarnya kejang. ${ }^{7,22}$ Efek samping fenitoin adalah diplopia, nistagmus, ataksia, sukar bicara (slurred speech), dan sedasi sehingga mengakibatkan gangguan perhatian dan konsentrasi. Perhatian dan konsentrasi diperlukan untuk proses registrasi dan pengenalan informasi. ${ }^{18}$

Kelemahan penelitian adalah rentang umur yang terlalu lebar dari subyek penelitian (6-12 tahun) dengan persentase kelompok umur 6-8 tahun yang lebih besar yaitu 56\%, dapat mempengaruhi hasil pemeriksaan daya ingat. Penelitian yang dilakukan di poliklinik anak dirasakan kurang nyaman sehingga mengganggu konsentrasi subyek saat menjalani tes daya ingat. Disimpulkan bahwa prevalensi gangguan daya ingat pada pasien epilepsi anak di RSUD Dr. Moewardi Surakarta 46\%. Lama pengobatan $>2$ tahun berpengaruh terhadap terjadinya gangguan daya ingat pada pasien epilepsi anak.

\section{Daftar pustaka}

1. Stafstrom CE. The pathophysiology of epileptic seizure: a primer for pediatricians. Pediatr Rev 1998;19:342-51.

2. Blum WT. Diagnosis and management of epilepsy. CMAJ 2003;168:441-8.

3. Mardjono M, Sidharta P. Neurologi klinis dasar. Edisi ke-9. Jakarta: Dian Rakyat; 2003.h.439-50.

4. Boer HM, Mula M, Sander JW. The global burden and stigma of epilepsy. Epilepsy \& Behavior 2008;12: 540-6.

5. Wical BS. New treatment option for pediatric epilepsy. Gillette Children's Specially Healthcare 2003;12:1-3.

6. Levefre F, Aronson N. Ketogenic diet for the treatment of refractory epilepsy in children: a systematic review of efficacy. Pediatrics 2000;105:1-7.

7. Manford M. Practical guide to epilepsy. Edisi ke-9. Burlington: Butterworth-Heinemann; 2003.h.3-17.

8. Donner EJ, Smith CR. Sudden unexplained death in children with epilepsy. Neurology 2001;57:430-4.

9. Callenbach PM, Westendorp RGJ, Geerts AT, Arts WFM, Peeters EAJ, Donselaar CA, dkk. Mortality risk in children with epilepsy: the Dutch study of epilepsy in childhood. Pediatrics 2001;107:1259-63.

10. Nevill BGR. Clinical review: epilepsy in childhood. BMJ 1997;315:924-30.

11. Cornaggia CM, Beghi M, Provenzi M, Beghi E. Correlation between cognition and behavior in epilepsy. Epilepsia 2006;47:s34-9.

12. Bortz JJ. Neuropsychiatric and memory issues in epilepsy. Mayo Clin Proc 2003;78:781-7.

13. Leung LS, McLachlan RS, Ma J. Behavior induced or disrupted by complex partial seizures. Neuroscience and Biobehavioral Reviews 2000;24:763-75.

14. Connor MJ. Epilepsy: nature, management, and memory. Epilepsia 1994;24:182-7.

15. Desai JD. Epilepsy and cognition. J Pediatr Neurosci 2008;3:16-27

16. Mazarati A. Epilepsy and forgetfulness: one impairment, multiple mechanism. Epilepsy Currents 2008;8:25-6.

17. Zeman A. The impairment of memory in epilepsy. Peninsula College of Medicine and Destistry 2006;3:S1820.

18. Baker GA, Hothersal AJ, Mallow JE. Memory. Epilepsy Action 2008;10:1-6.

19. Faught RE. Where is memory. Medscape J 2002;1-3.

20. Zhang J. Memory process and the function of sleep. Journal of Theoritics 2004;6:1-7.

21. Shehata GA, Bateh AEM, Hamed SA. Neuropsychological effects of antiepileptic drugs (carbamazepine versus valproate) in adult males with epilepsy. Neuropsychiatric Disease and Treatment 2009;5:527-533.

22. Gupta R, Ravat SH. Antiepileptic drugs in pediatric epilepsy. J Pediatr Neurosci 2008;3:7-14. 